\title{
Effect of 2-amino oleic acid exposure conditions on the inhibition of calcification of glutaraldehyde cross-linked porcine aortic valves
}

\author{
Weiliam Chen, ${ }^{1}$ John D. Kim, ${ }^{1}$ Frederick J. Schoen, ${ }^{2}$ and Robert J. Levy ${ }^{1, *}$ \\ ${ }^{1}$ Division of Pediatric Cardiology, University of Michigan Medical Center, Ann Arbor, Michigan 48109-0576; \\ ${ }^{2}$ Department of Pathology, Brigham and Women's Hospital and Harvard Medical School, Boston, Massachusetts 02115
}

Postimplant calcific degeneration is a frequent cause of clinical failures of glutaraldehyde cross-linked porcine bioprosthetic heart valves (BPHV). It was demonstrated previously that 2-amino oleic acid (AOA) used as a bioprosthesis treatment was highly effective in mitigating aortic valve cusp but not aortic wall calcification. Our main objective was to study the efficacy of various AOA exposure conditions for inhibiting calcification of both cusps and aortic wall tissues using rat subdermal implants. BPHV tissues were treated with a saturated AOA solution for different time intervals before experimentation. Aortic wall AOA levels were consistently lower than that of the cusps after the same exposure times. The diffusion of calcium ion across both cusp and aortic wall tissues was evaluated, and the results demonstrated that there was an AOA exposure time-dependent retardation of calcium ion penetration for cusp but not aortic wall. An 8-month extraction study was performed to determine the stability of AOA binding. When Tween 80 was used as an extraction medium, cusp and aortic wall retained 12.9 and $48.7 \%$, respectively, of their initial AOA levels. AOA inhibition of calcification in rat subdermal implants (60 days) was found to be exposure time-dependent with maximum treatment time $(120 \mathrm{~h})$, resulting in the lowest calcium levels $(20.1 \pm 10.3$ and $71.4 \pm 5.4 \mu \mathrm{g} / \mathrm{mg}$ of cusp and aortic wall, respectively) as compared with controls $(219.1 \pm 6.8$ and $104.9 \pm 8.5 \mu \mathrm{g} / \mathrm{mg}$ of cusp and aortic wall, respectively). The significance of AOA binding on BPHV tissue was determined by either blocking or reducing BPHV's (cusp and aortic wall) free aldehyde residues with lysine or $\mathrm{NaBH}_{4}$, respectively, before AOA treatment. For aortic cusps, the AOA contents after $72 \mathrm{~h}$ were $98.3 \pm 2.7$, $34.2 \pm 3.6$, and $54.1 \pm 3.0 \mathrm{nM} / \mathrm{mg}$ of tissue for AOA (control), lysine-pretreated (plus $\mathrm{AOA}$ ) and $\mathrm{NaBH}_{4}$-pretreated (plus AOA) tissues, respectively. However, their calcium levels after 60 days of rat subdermal implant were all comparable (i.e., $48.1 \pm 6.2,38.2 \pm 9.1$, and $47.0 \pm 15.0 \mu \mathrm{g}$ calcium per mg of tissue). Similar results were observed on BPHV aortic wall. It can thus be concluded that AOA inhibition of BPHV calcification is exposure time-dependent, but the efficacy of AOA for aortic wall is less than that noted for aortic cusps, perhaps because of lower AOA binding and differences in calcium diffusion kinetics. (C) 1994 John Wiley \& Sons, Inc.

\section{INTRODUCTION}

Pathologic calcific degeneration frequently causes clinical failure of bioprosthetic heart valves (BPHV) fabricated from porcine aortic valves cross-linked with glutaraldehyde. ${ }^{1}$ Calcification of glutaraldehyde cross-linked bioprosthetic heart valves is hypothesized to be a multifactorial process. ${ }^{2}$ The influx of calcium ions over time into bioprosthetic tissue after BPHV implantation almost certainly plays an important role in the initial nucleation of calcium phosphate crystals intrinsically within devitalized cells in the

\footnotetext{
*To whom correspondence should be addressed at: R5014 Kresge II, Division of Pediatric Cardiology, C. S. Mott Children's Hospital, University of Michigan Medical Center, Ann Arbor, MI 48109-0576.
}

valve cusps. $^{2-4}$ This results in calcific degeneration, and eventually failure due to stenosis or tearing with regurgitation. Various strategies have been evaluated for counteracting this mineralization process. Nevertheless, no completely satisfactory method is currently available clinically for completely preventing calcification of BPHV. However, 2-amino oleic acid (AOA) as a BPHV pretreatment was shown to be effective in preventing calcification of glutaraldehyde cross-linked aortic valve cusps, but not aortic wall. ${ }^{5-7}$ These recent animal model studies used rat subdermal implants, ${ }^{5}$ sheep orthotopic mitral valve replacements, ${ }^{6}$ and xenografts composed of porcine trileaflets and ascending aortic wall implanted as left ventricular apicoaortic shunts ${ }^{7}$ in sheep. AOA is hypothesized to bind to BPHV via its 2-amino group reacting with residual glutaraldehyde (presumably 
forming a Schiff base or related compounds ${ }^{8-10}$ ) thereby allowing AOA to remain in the tissue.

The objective of this study was to investigate the conditions critical for AOA mitigation of calcification of both glutaraldehyde-pretreated aortic valve cusps and aortic wall. The following studies were carried out to examine: 1) the effects of various exposure conditions for AOA incorporation on calcium diffusion through either cusp or aortic wall; 2) the long-term binding stability of AOA to either cusp or valve (by comparing dissociation into three types of media: a physiologic buffer, bovine serum, and a nonionic detergent solution); 3) the calcification of rat subdermal implants for assessing the inhibition of calcification for either cusp or aortic wall using tissues that were exposed to AOA for various durations of time; 4) the effects of inhibiting AOA binding to both glutaraldehyde-pretreated aortic valve cusps and aortic wall on the calcification response by either partially blocking AOA uptake with lysine or reducing the residual aldehyde groups with sodium borohydride before AOA exposure.

\section{MATERIALS AND METHODS}

\section{Materials}

${ }^{14}$ C-labeled 2-amino oleic acid (AOA) (labeled at the $\beta$-carbon, specific activity: $1.6 \mathrm{mCi} / \mathrm{mM}$ ) was synthesized at American Radio Chemical (St. Louis, MO) using procedures established by Girardot. ${ }^{11}$ Nonradioactive AOA was synthesized by the same procedures at Medtronic (Minneapolis, MN). Fresh porcine aortic valves were obtained at slaughter and glutaraldehyde cross-linked porcine aortic valve tissues (prepared according to proprietary procedures approved for clinical use) were directly supplied by the Heart Valve Division of Medtronic (Irvine, CA). Fresh frozen bovine serum, lysine, and sodium borohydride were purchased from Sigma Chemical Company (St. Louis, MO). Tween 80 was from Fisher Chemical (Fairlawn, NJ). Sodium azide (Sigma Chemical Company) was added to the bovine serum as a preservative $(0.1 \%)$. All other chemicals were reagent grade; distilled and deionized water was used.

Amino-oleic acid was provided to our laboratory by the Medtronic Heart Valve Division (Irvine, CA) as a saturated solution prepared under proprietary conditions also used to prepare clinically implantable heart bioprostheses. ${ }^{6,11} \mathrm{~A}{ }^{14} \mathrm{C}$-AOA stock solution was prepared by similar procedures. ${ }^{6,11}$ The ${ }^{14} \mathrm{C}$-AOA stock solution was spiked directly into the AOA solution for all experiments. AOA binding postglutaraldehyde fixation involved incubations of either porcine aortic cusps or aortic wall specimens in a saturated solution of AOA in a proprietary AOA solvent as described before, for the various durations described subsequently for the dose response conditions. Tissues pretreated with ${ }^{14} \mathrm{C}-\mathrm{AOA}$ were washed extensively with an excess of normal saline until the radioactivity of the wash liquid was indistinguishable from background. Control tissues were exposed to the proprietary AOA-solvent (without AOA) for appropriate durations.

\section{Determination of AOA content in ${ }^{14} \mathrm{C}$-AOA-treated tissues}

Sample tissues were lyophilized separately, weighed, and incubated in Solvable ${ }^{\circledR}$ (New England Nuclear Research Products, Boston, MA) for $24 \mathrm{~h}$ at $60-65^{\circ} \mathrm{C}$ in a water bath. Each digested sample was then combined with an adequate volume of Ecolume ${ }^{\oplus}$ (ICN Biomedical, Irvine, CA), and its ${ }^{14} \mathrm{C}$ radioactivity was determined by liquid scintillation counting (Beckman LS3801 Liquid Scintillation Counter, Beckman Instruments, Fullerton, CA). The AOA content of each tissue specimen was assessed by comparing its dpm value with that of the ${ }^{14} \mathrm{C}-\mathrm{AOA}$ solution prepared for tissue treatment. The amount of AOA incorporated was expressed as nanomoles per milligram of dried tissue.

\section{AOA uptake by tissues}

Porcine aortic valve cusp or wall AOA uptake studies were separately performed by incubating glutaraldehyde cross-linked tissues with ${ }^{14} \mathrm{C}$-AOA solution for different periods of time $(0.17,1,3,6,12,24,72$, and $96 \mathrm{~h}$ ) at $37^{\circ} \mathrm{C}$. The tissues' AOA contents were determined on freeze-dried representative samples (as before).

\section{Diffusion of calcium across tissues}

A piece of AOA-treated cusp tissue was mounted on a microdiffusion cell. One milliliter of $0.2 \%$ (18 $\mathrm{mM}$ ) calcium chloride solution was pipetted into the donor chamber and $1 \mathrm{ml}$ of water was immediately added to the recipient chamber. The diffusion cell was placed on a shaker rotating at $120 \mathrm{rpm}$, and the temperature was maintained at $37^{\circ} \mathrm{C}$. After $5 \mathrm{~min}$, the recipient chamber was evacuated and replenished 
with $1 \mathrm{ml}$ of water. Additional samples were withdrawn at 10,15, 20,30,45, 60 and $75 \mathrm{~min}$. The calcium contents of all samples collected (after proper dilutions) were determined by atomic absorption spectroscopy (Perkin-Elmer Model 2380 Spectrophotometer, Perkin-Elmer, Norwalk, CT) at a wavelength of $422.8 \mathrm{~nm}$.

Similar methodologies were applied to evaluate the pattern of calcium diffusion across aortic wall. Various samples were withdrawn between 3 and $48 \mathrm{~h}$. Their diffusivities were calculated based on steadystate equilibrium, ${ }^{12}$ as described by Johnston et al. ${ }^{13}$ using the following equation ${ }^{12}$ :

$$
\mathrm{D}=\mathrm{I}^{2} / 6\left(\mathrm{t}_{\text {lag }}\right) \text {, }
$$

where $D=$ diffusivity, $I=$ thickness of tissue, and $t_{\text {lag }}=$ lag time.

\section{AOA extraction study}

${ }^{14} \mathrm{C}$-AOA extraction studies were carried out with three individual solvents including $\mathrm{pH} 7.4$ phosphate-buffered saline, $20 \%$ aqueous Tween 80 solution (to provide a sink condition for AOA dissolution), and bovine serum (to simulate an in vivo environment after valve implantation). Samples of AOAtreated tissue were transferred to a vial containing 10 $\mathrm{ml}$ of $\mathrm{pH} 7.4$ sodium phosphate-buffered saline $(0.18 \mathrm{M})$ placed on a shaker (rotating at $120 \mathrm{rpm}$ ) at $37^{\circ} \mathrm{C}$ for $0.5 \mathrm{~h}$. Each BPHV specimen was then transferred to another vial containing fresh phosphate buffer. The same procedure was repeated at different time intervals for 8 months. Samples were withdrawn from each vial and combined with Ecolume ${ }^{\circledR}$, and the ${ }^{14} \mathrm{C}$-level was assessed by liquid scintillation counting. AOA content was determined by comparing its $\mathrm{dpm}$ value with that of the ${ }^{14} \mathrm{C}$-spiked $\mathrm{AOA}$ solution used for treating tissue. At the conclusion of the extraction study, each tissue specimen was retrieved and digested with Solvable ${ }^{(8)}$; its residual ${ }^{14} \mathrm{C}$ radioactivity was determined by the procedures previously described involving saline washes to remove residual radioactivity followed by lyophilization. The residual $\mathrm{dpm}$ value was added to the total cumulative counts gathered during the study; this number was stipulated as the initial total counts on the tissue before the experiment. The extraction study results were thereby expressed as the cumulative percentage of $\mathrm{AOA}$ extracted versus time.

Similar methodologies were applied to conduct separate extraction studies using either bovine serum or Tween 80 as extraction media.

\section{Treatment of tissues (cusp and aortic wall) for subdermal implants}

Cusps were pretreated with a saturated AOA solution $(0.171 \%)$ (approximately $1 \mathrm{ml} \mathrm{AOA}$ solution for
$20 \mathrm{mg}$ of wet tissue) for $10 \mathrm{~min}, 5,72$, and $120 \mathrm{~h}$ to incorporate various amounts of AOA into the tissues. Control cusp specimens were treated with only AOA solvent for the same durations. Similarly, aortic wall samples were treated with AOA solution for 2, 12, 72, and $120 \mathrm{~h}$. A set of aortic wall tissues was also treated with AOA solvent for the same durations as control.

We sought to reduce the reactivity of free glutaraldehyde residuals for AOA binding. Porcine aortic cusp and aortic wall tissues were incubated in a 0.17 $\mathrm{M}$ lysine solution at room temperature for $24 \mathrm{~h}$. These lysine treated tissues were washed extensively with normal saline and subsequently treated with AOA solution for $72 \mathrm{~h}$ according to the procedures described previously.

To reduce the free glutaraldehyde residuals for inhibiting subsequent AOA binding, porcine aortic valve cusp and wall tissues were incubated in $0.1 \mathrm{M}$ $\mathrm{NaBH}_{4}$ in $0.05 \mathrm{M} \mathrm{N}$-2-hydroxyethylpiperazine- $N^{\prime}-2$ ethanesulfonic acid (Hepes) buffer (at pH 7.4) at room temperature for $24 \mathrm{~h}$. These $\mathrm{NaBH}_{4}$-treated tissues were washed with normal saline and subsequently treated with AOA for $72 \mathrm{~h}$ according to the procedures described previously.

\section{Efficacy of AOA for inhibiting glutaraldehyde-pretreated porcine aortic cusp and aortic wall calcification in a rat subdermal model}

Rat subdermal implants ${ }^{14,15}$ were used to assess the anticalcification efficacy of AOA. AOA-treated, solvent-treated, and untreated tissues were implanted into male weaning rats ( 3 weeks old, $50-60 \mathrm{~g}$, Sprague-Dawley; Charles River Laboratories, Burlington, MA), anesthetized with a mixture of ketamine $(100 \mathrm{mg} / \mathrm{ml})$ and xylazine $(20 \mathrm{mg} / \mathrm{ml})$, in subdermal pouches dissected in the ventral abdominal wall as described previously. ${ }^{15}$ Each animal received two separate subdermal implants. After 60 days, rats were euthanized with carbon dioxide and the tissue specimens were retrieved. Representative specimens fixed with a combined glutaraldehyde-formaldehyde fixative ${ }^{16}$ solution were examined morphologically by light microscopy, using glycomethacrylate embedding medium according to previously described methods. ${ }^{4,14,17}$ All tissue specimens were rinsed with normal saline and deionized water and freeze dried. Acid hydrolysates of the freeze-dried specimens were prepared for calcium analysis by atomic absorption spectroscopy using previously described procedures. $^{4,15}$

\section{Data and statistical analyses}

Replicate data was calculated and expressed as mean \pm standard error of the mean (SEM). Unpaired 
$t$ tests were used to assess the significance of statistical differences between experimental groups and controls.

\section{RESULTS}

\section{AOA uptake by tissues}

Incubation time-dependent uptake between AOA and tissue samples, assayed as the amounts of AOA incorporated into cusp and aortic wall, is depicted in Figure 1. Increased duration of AOA incubation resulted in plateau levels of AOA by approximately 20 $h$ for both aortic wall and cusp; slight increases in AOA levels could be seen after that time with lengthier incubations. Uptake normalized according to dry weight at all times was significantly greater for cusp than aortic wall; the maximum amounts of AOA incorporated initially into cusp and aortic wall were 127.9 and $67.3 \mathrm{nM} / \mathrm{mg}$ of tissue, respectively $(P<$ $.001)$.

\section{Diffusion of calcium across tissues}

The rate of calcium diffusion was more than an order of magnitude more rapid across cusp (AOA pretreated and untreated) than aortic wall (AOA pretreated and untreated) tissues (Fig. 2). In Figure 2A, after $1 \mathrm{~h}$, the cumulative amounts of calcium diffused

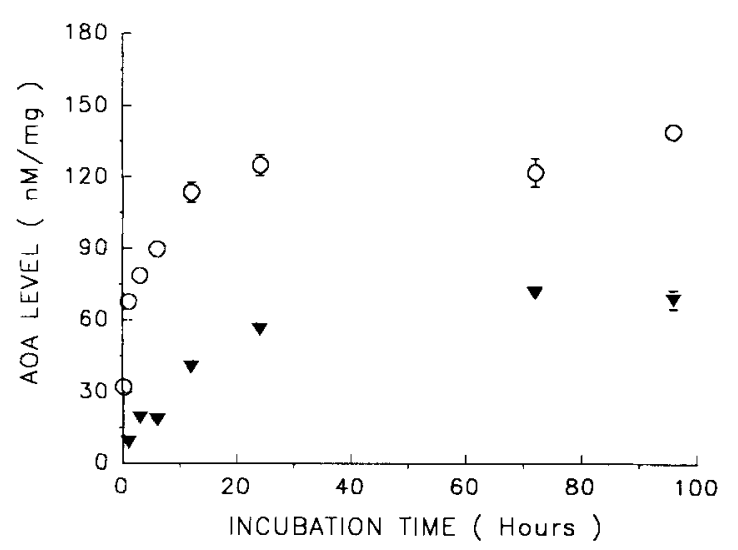

Figure 1. Uptake of AOA by bioprosthetic tissue: (open circles) cusp and (closed triangles) aortic wall. This study was performed to establish the optimum treatment for incorporating various amounts of AOA into tissues for the duration of exposure. The actual AOA levels of the tissues for implantation were determined independently. Each data point represents the average of at least six replicates \pm SEM. Copyright (C) 1994 John Wiley \& Sons, Inc. Reprinted from Polymer Site-Specific Pharmacotherapy, pp. 221-242, by W. Chen, S. P. Schwendeman, V. Labhasetwar, and R. J. Levy. Used with permission. All rights reserved.
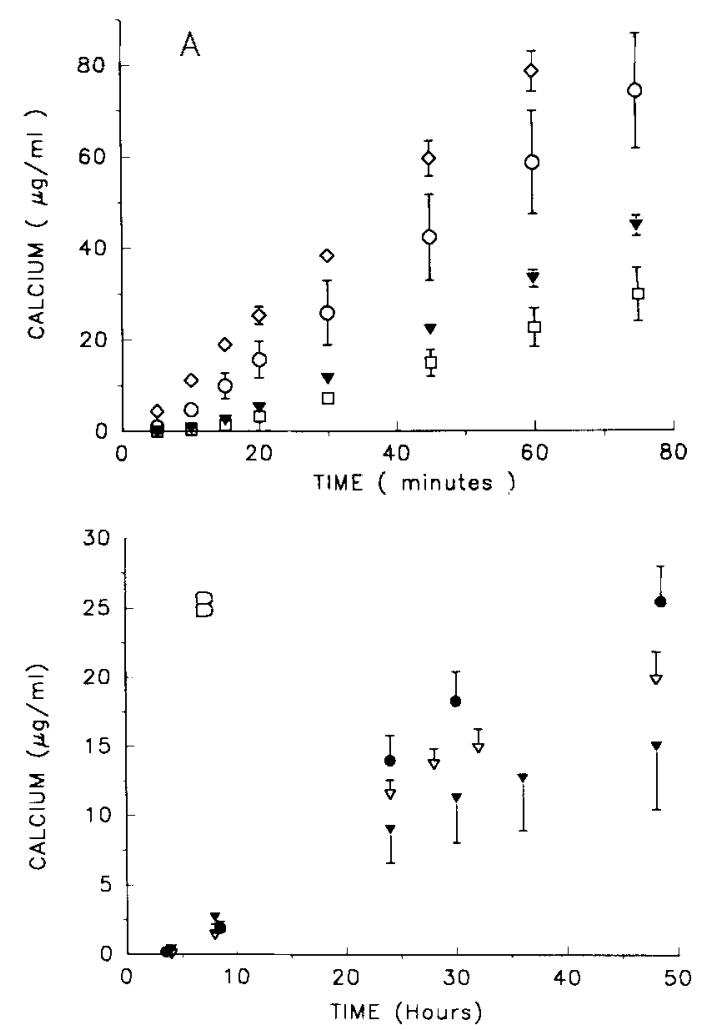

Figure 2. (A) Diffusion of calcium across cusp tissues with different AOA levels: (open squares) $101.0 \mathrm{nM} / \mathrm{mg}$ of tissue, (closed triangles) $59.4 \mathrm{nM} / \mathrm{mg}$ of tissue, (open circles) $32.1 \mathrm{nM} / \mathrm{mg}$ of tissue, and (open diamonds) $0 \mathrm{nM} / \mathrm{mg}$ of tissue. (B) Diffusion of calcium across aortic wall tissues with different AOA levels: (closed triangles) $60.2 \mathrm{nM} / \mathrm{mg}$ of tissue, (open triangles) $23.0 \mathrm{nM} / \mathrm{mg}$ of tissue and (closed circles) $0 \mathrm{nM} / \mathrm{mg}$ of tissue. Each data point represents the average of at least four replicates \pm SEM.

across cusp samples were $22.5 \pm 3.6,48.7 \pm 10.8$, and $78.1 \pm 3.1 \mu \mathrm{g}$ (Average \pm SEM) for tissues containing $101.8,32.1$, and $0 \mathrm{nM}$ of AOA per mg tissue, respectively. When aortic wall was used as a diffusion barrier (Fig. 2B), after approximately $48 \mathrm{~h}$ the cumulative amounts of calcium diffused were $14.9 \pm 3.2,19.7 \pm$ 1.8 , and $25.4 \pm 2.2 \mu \mathrm{g}$ for tissues containing 60.2 , 23.0, and $0 \mathrm{nM}$ of AOA per $\mathrm{mg}$ of tissue, respectively. Overall, the increased presence of AOA significantly retarded only diffusion of calcium ions across aortic cusp (compared with control), but not aortic wall (Table 1), as indicated by their calculated diffusivities.

\section{AOA extraction study}

The results of the 8-month extraction study using both cusp and aortic wall are illustrated in Figure 3. In general, an initial burst of AOA released from each type of tissue specimen within the first $24 \mathrm{~h}$ of in vitro incubation followed by a greatly diminished rate of AOA extraction. Extraction of AOA from cusps was approximately $125 \%$ greater than that of aortic wall. 
TABLE I

Diffusivities of Calcium Ions Comparing Cusp and Aortic Wall with Different AOA Levels

\begin{tabular}{lcc} 
Tissue & $\begin{array}{c}\text { AOA Level } \\
(\mathrm{nM} / \mathrm{mg} \text { Tissue })\end{array}$ & $\begin{array}{c}\text { Diffusivity } \\
\left(\mathrm{mm}^{2} / \mathrm{h}\right)\end{array}$ \\
\hline Cusp & 0 & $2.69 \pm 0.11$ \\
& 32.1 & $1.22 \pm 0.20^{*}$ \\
Aortic wall & 101.8 & $0.81 \pm 0.11^{*}$ \\
& 0 & $0.21 \pm 0.04$ \\
& 23.0 & $0.09 \pm 0.00^{+}$ \\
& 60.2 & $0.14 \pm 0.00^{+}$ \\
\hline
\end{tabular}

Each number represents at least four replicates \pm SEM.

${ }^{*} P<.01$ as compared with no AOA incorporation.

${ }^{+} P<.01$ as compared with no AOA incorporation.

\section{Cusp AOA}

As seen in Figure 3A, an initial burst of AOA release from cusps was observed in both bovine serum and Tween solution. A very large proportion of bound AOA was dissociated in these solvents within the first $24 \mathrm{~h}$. The rate of dissociation greatly moder-
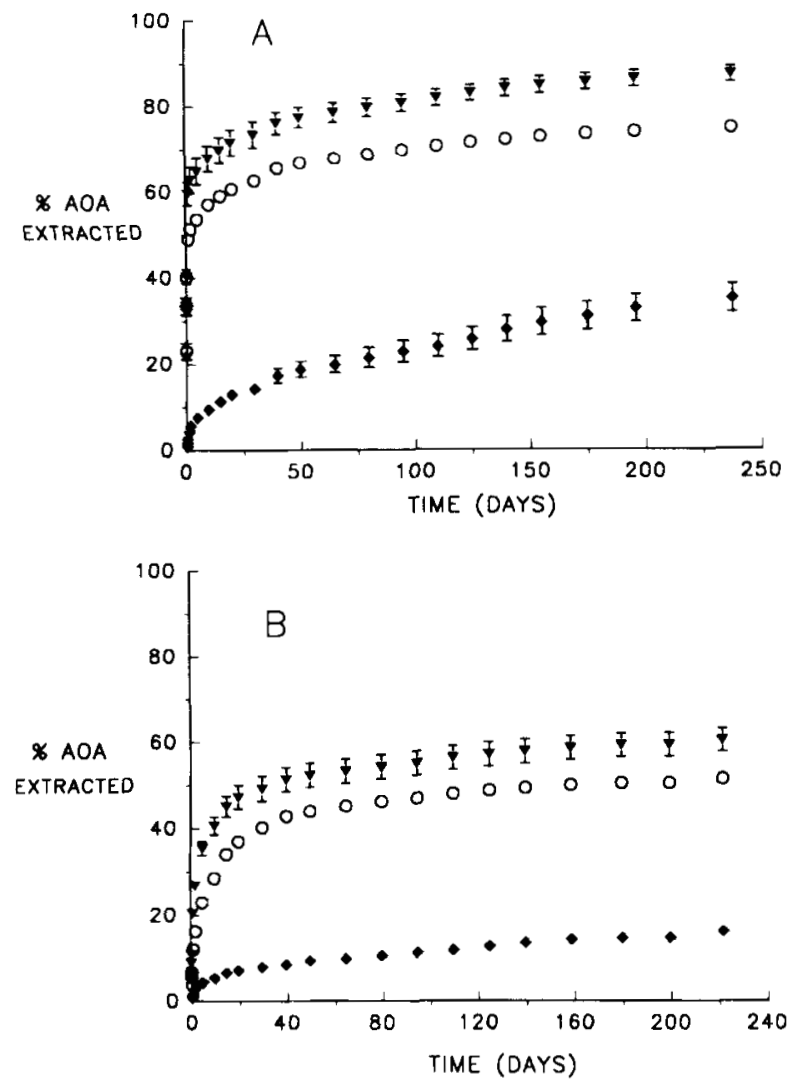

Figure 3. (A) Extraction of AOA treated cusp tissue in: (closed triangles) $\mathrm{pH} 7.4$ phosphate buffer, (open circles) bovine serum, and (closed triangles) Tween 80 solution. (B) Extraction of AOA-treated aortic wall tissue in: (closed diamonds) $\mathrm{pH} 7.4$ phosphate buffer, (open circles) bovine serum, and (closed triangles) Tween 80 solution. Each datapoint represents the average of at least five replicates \pm SEM. ated thereafter and reached a relatively steady (or linear) phase after 50 days. The rate of $\mathrm{AOA}$ dissociation was relatively lower in phosphate-buffered saline compared with bovine serum and Tween.

Table II summarizes the initial and residual AOA levels on the cusp specimens used for the extraction study. For comparison, fresh porcine aortic cusp tissue (after AOA pretreatment) was used as a control. It should be noted that $42.2 \pm 2.3 \mathrm{nM}$ of $\mathrm{AOA}$ was present on each milligram of fresh cusp tissue (nonextracted) as compared with $176.6 \pm 7.1 \mathrm{nM}$ per milligram of its glutaraldehyde cross-linked counterpart (before extraction). Each milligram of cusp tissue, after extraction with phosphate buffer, retained $114.8 \pm$ $5.2 \mathrm{nM}$ of AOA (65.0\% of initial tissue level). The presence of a surfactant (i.e., Tween 80 ) in the extracting media greatly enhanced AOA's aqueous solubility and dissociation; thus, only $22.8 \pm 2.8 \mathrm{nM}$ of AOA (12.9\% of initial tissue level) remained on each milligram of tissue at the conclusion of the study. When bovine serum was used as an extraction medium, each milligram of cusp tissue retained $44.9 \pm$ $1.7 \mathrm{nM}$ of AOA (25.4\% of initial tissue level).

\section{Aortic wall AOA}

In Figure 3B, similar to the cusp results, an initial burst effect was also observed in either bovine serum or Tween solution. A large portion of AOA was dissociated in the first 10 days. The rate of dissociation greatly moderated thereafter and reached a steady phase after 40 days. Similar to the observations in the cusp tissues, the rate of AOA dissociation in phosphate buffer remained slow throughout the study compared to the other media studied. Table III summarizes the initial and residual AOA levels on the cusp tissues used for the extraction study. For com-

TABLE II

Residual Porcine Aortic Cusp AOA Levels after Extraction Study

\begin{tabular}{lcc}
\hline \multicolumn{1}{c}{ Medium } & $\begin{array}{c}\text { Amount of AOA } \\
\text { (nM/mg Tissue) }\end{array}$ & (\% Control) \\
\hline Control $^{*}$ & $176.6 \pm 4.7$ & \\
Bovine serum $^{\dagger}$ & $44.9 \pm 1.7$ & 25.4 \\
20\% Tween $80^{\dagger}$ & $22.8 \pm 2.8$ & 12.9 \\
Phosphate buffer $^{+}$ & $114.8 \pm 4.7$ & 65.0 \\
Fresh tissue $^{\ddagger}$ & $42.2 \pm 2.3^{\S}$ & 23.9 \\
\hline
\end{tabular}

Each number represents at least five replicates \pm SEM. The AOA levels on both types of tissue after the extraction study were significantly lower than those of the controls ( $P$ $<.001$ in both cases).

*No extraction study performed.

'Results after 240 days of extraction.

${ }^{\ddagger}$ Nonglutaraldehyde cross-linked tissue subjected to AOA pretreatment/no extraction study performed.

${ }^{\S}$ Adopted from Chen et al. ${ }^{7}$ 
TABLE III

Residual Porcine Aortic Wall AOA Levels after Extraction Study

\begin{tabular}{lcc}
\hline \multicolumn{1}{c}{ Medium } & $\begin{array}{c}\text { Amount of AOA } \\
\text { (nM/mg Tissue) }\end{array}$ & (\% Control) \\
\hline Control $^{*}$ & $59.1 \pm 1.6$ & \\
Bovine serum $^{\dagger}$ & $28.8 \pm 0.2$ & 48.7 \\
20\% Tween $80^{\dagger}$ & $23.5 \pm 1.4$ & 39.8 \\
Phosphate buffer $^{\dagger}$ & $55.5 \pm 0.3$ & 93.9 \\
Fresh tissue $^{\ddagger}$ & $26.6 \pm 1.2 \S$ & 45.0 \\
\hline
\end{tabular}

Each number represents at least five replicates \pm SEM. The AOA levels on both types of tissue after the extraction study were significantly lower than those of the controls $(P$ $<.001$ in both cases).

*No extraction study performed.

${ }^{+}$Results after 240 days of extraction.

${ }^{\ddagger}$ Nonglutaraldehyde cross-linked tissue subjected to AOA pretreatment/no extraction study performed.

${ }^{\S}$ Adopted from Chen et al. ${ }^{7}$

parison, fresh tissue (after AOA pretreatment) was used as a control; $26.6 \pm 1.2 \mathrm{nM}$ of AOA was present on each milligram of fresh aortic wall tissue (nonextracted) as compared with $59.1 \pm 1.6 \mathrm{nM}$ per milligram of its glutaraldehyde cross-linked counterpart (before extraction). Each milligram of aortic wall tissue, after extraction with phosphate buffer, retained $55.5 \pm 0.3 \mathrm{nM}$ of AOA (93.9\% of initial AOA level). The presence of a surfactant (i.e., Tween 80 ) greatly enhanced AOA's aqueous solubility and dissociation; thus, only $23.5 \pm 1.4 \mathrm{nM}$ of AOA (48.7\% of initial tissue level) remained on each milligram of aortic wall tissue at the conclusion of the study. When bovine serum was used as an extraction medium, each milligram of aortic wall tissue retained $28.8 \pm 0.2 \mathrm{nM}$ of AOA (39.8\% of initial tissue level).

\section{Efficacy of AOA (duration of exposure study) using rat subdermal model}

The extent of inhibition of calcification on AOA treated cusp and aortic wall with respect to their durations of AOA exposure, after 8 weeks of subdermal implantation, is illustrated in Figures 4 and 5.

\section{Cusp calcification mitigation}

In Figure 4A, the calcium levels of explanted cusp tissue specimens decrease with the increase of $A O A$ exposure time. A sharp decline of calcium from 150.6 \pm 24.0 to $48.1 \pm 6.2 \mu \mathrm{g} / \mathrm{mg}$ of tissue was observed at 5 and $72 \mathrm{~h}$ of AOA exposure, respectively. The lowest cuspal calcium level ( $20.1 \pm 10.3 \mu \mathrm{g} / \mathrm{mg}$ of tissue) was achieved at $120 \mathrm{~h}$ of AOA treatment. All of the vari-
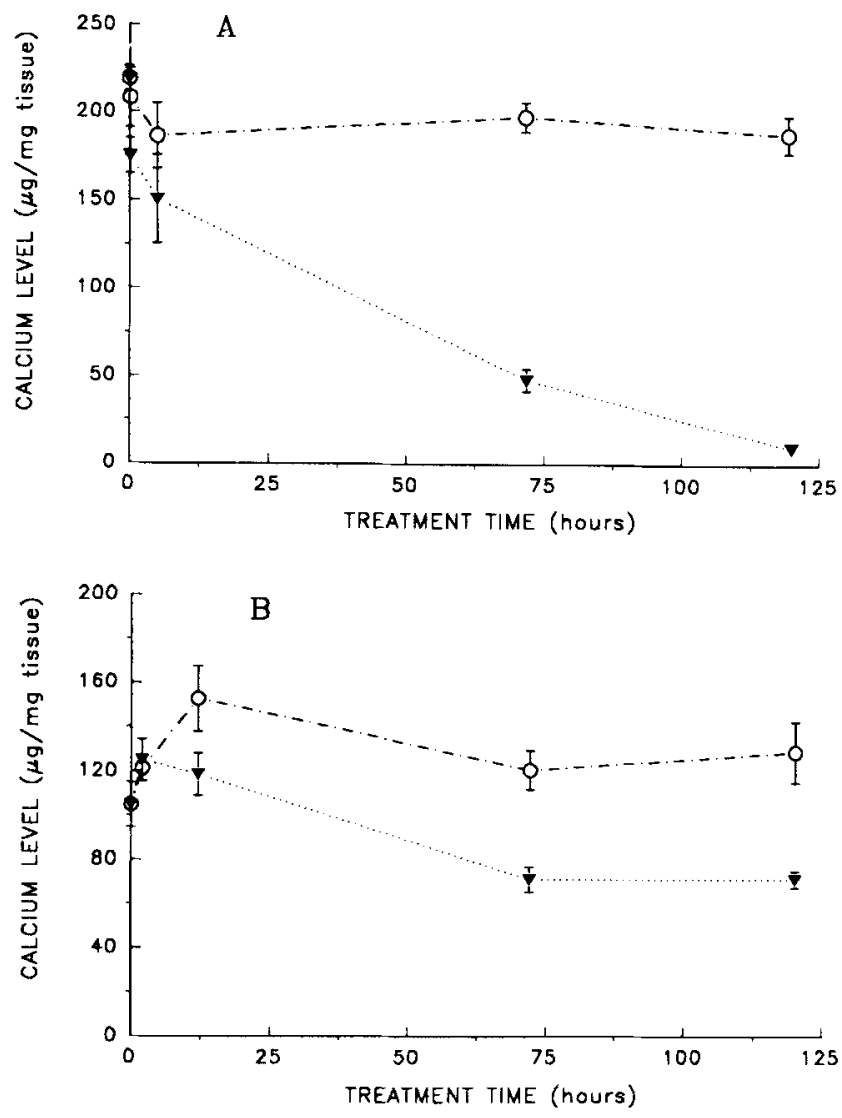

Figure 4. (A) Calcification of cusp tissues with different AOA exposure durations after 60 days of subdermal implantation: (closed triangles) AOA-treated and (open circles) control. (B) Calcification of aortic wall tissues with different $A O A$ exposure durations after 60 days of subdermal implantation: (closed triangles) AOA-treated and (open circles) control. Controls were exposed for the same durations as AOA specimens, but only in solvent. Each data point represents the average of at least 10 replicates \pm SEM.

ous control specimens (treated only with AOA solvent for durations identical to the corresponding AOA incubations) showed virtually identical elevated calcium levels, indicating that AOA treatment, but not solvent exposure, is a prerequisite for anticalcification.

Aortic Wall Calcification Inhibition

For aortic wall (Fig. 4B), the shortest exposure time $(2 \mathrm{~h})$ was ineffective for preventing calcification. When exposure time was $12 \mathrm{~h}$, the calcium content decreased to $71.4 \pm 5.4 \mu \mathrm{g} / \mathrm{mg}$ of tissue manifesting a significant difference in calcium levels compared with control. Nevertheless, the aortic wall explants were more calcified than cusp, which indicated that aortic wall calcification is influenced less by AOA pretreatment than cusp. 

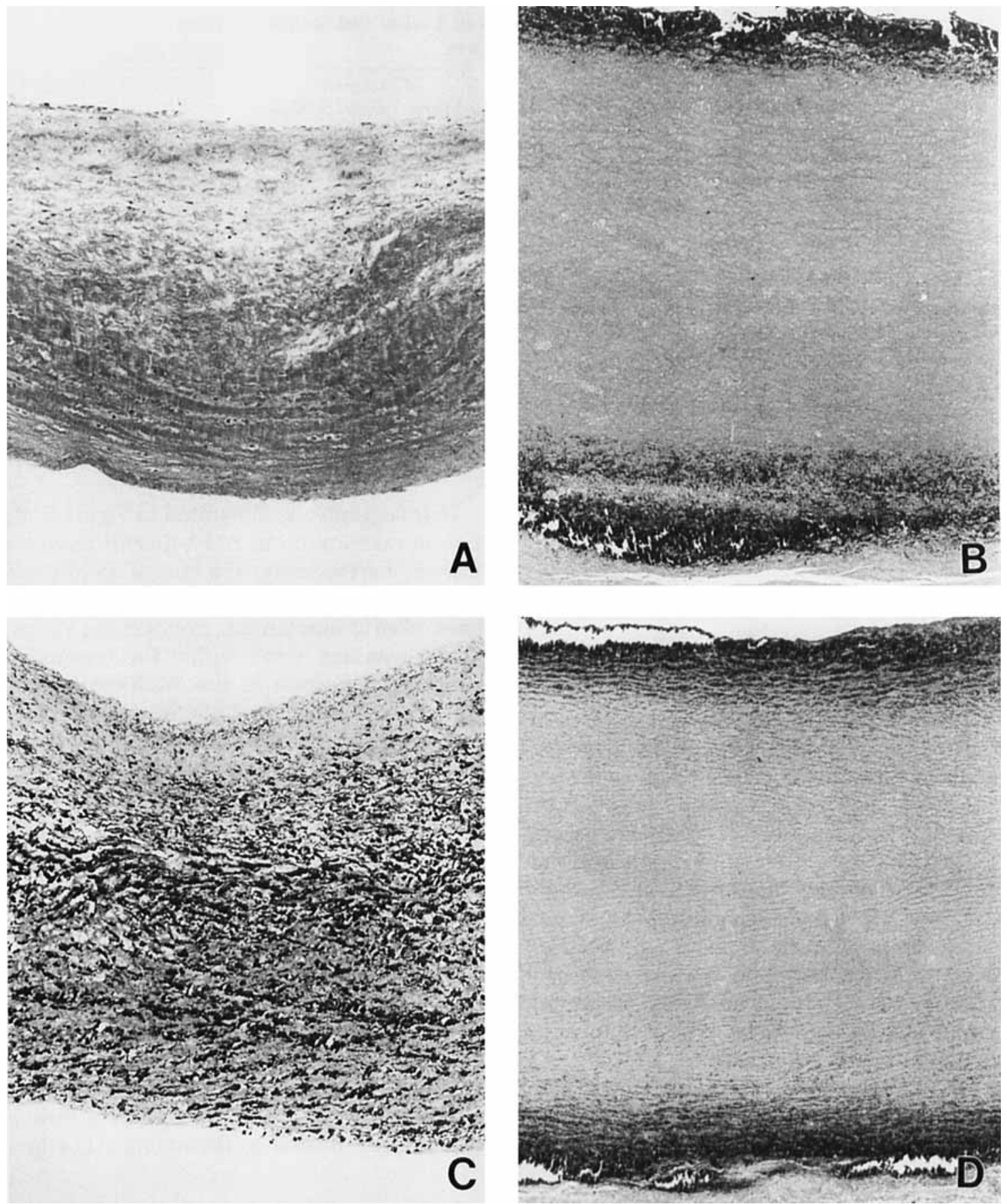

Figure 5. Morphologic demonstration of substantial inhibition of calcification of porcine aortic valve cusp by maximal concentration AOA pretreatment, but lesser effect on aortic wall. (A) AOA treated cusp; minimal calcification noted (compare with [C]). (B) AOA-treated aortic wall; no detectable decrease in calcification from control (compare with [D]). (C) Control (not AOA-treated) cusp; severe calcification. (D) Control (not AOA-treated) aortic wall; calcification is equivalent to that in [B]. All implanted subdermally in rats for 60 days. All are photographs of sections stained with von Kossa stain (calcium phosphate black); magnifications: $(A)$ and (C) $\times 150,(B)$ and (D) $\times 50$.

Efficacy of AOA (pre-AOA blockade of residual aldehyde groups with lysine and reduction of residual aldehyde groups with sodium borohydride) in rat subdermal model

\section{Cusp: lysine and borohydride data}

Table IV summarizes the calcium levels of cusp tissues and their corresponding AOA levels. Before im- plantation, the AOA contents were $98.3 \pm 2.7,34.2 \pm$ 3.6 , and $54.1 \pm 3.0 \mathrm{nM} / \mathrm{mg}$ of tissue for AOA (control), lysine-pretreated (plus $\mathrm{AOA}$ ) and $\mathrm{NaBH}_{4}$ pretreated (plus AOA) tissues, respectively indicating reduced AOA levels as a result of the preexposures to either lysine or sodium borohydride. After 60 days of subdermal implantation, the calcium levels of the explants were comparable (i.e., $48.1 \pm$ 
TABLE IV

Effects on Calcification (60-Day Rat Subdermal Implant) of Lysine and $\mathrm{NaBH}_{4}$ Pretreatment Before AOA on Aortic Cusp

\begin{tabular}{llcr}
\hline Group & \multicolumn{1}{c}{ Treatment } & $\begin{array}{c}\text { AOA Level } \\
\text { (nM/mg Tissue) } \pm \text { SEM }\end{array}$ & $\begin{array}{c}\text { Tissue Calcium } \\
(\mu \mathrm{g} / \mathrm{mg} \text { tissue) } \pm \text { SEM }\end{array}$ \\
\hline I & Control (no treatment) & 0 & $219.1 \pm 6.8$ \\
II & AOA treatment & $98.3 \pm 2.7$ & $48.1 \pm 6.2^{*++}$ \\
III & Lysine/then AOA treatment & $34.2 \pm 3.6$ & $38.2 \pm 9.1^{*}$ \\
IV & Lysine only & 0 & $159.3 \pm 5.8$ \\
V & $\mathrm{NaBH}_{4} /$ then AOA treatment & $541 . \pm 3.0$ & $47.0 \pm 15.0^{*}$ \\
VI & $\mathrm{NaBH}_{4}$ only & 0 & $197.6 \pm 7.2$ \\
\hline
\end{tabular}

Each data point represents the average of at least 10 replicates \pm SEM.

${ }^{*} P<.001$ as compared with group I.

${ }^{+} P<.001$ as compared with groups IV and $V$.

$6.2,38.2 \pm 9.1$, and $47.0 \pm 15.0 \mu \mathrm{g}$ of calcium per $\mathrm{mg}$ of tissue), and significantly less than that of control ( $P$ $<.001$ ). The control tissues (i.e., without any AOA treatment) showed high degrees of calcification (i.e., $219.1 \pm 6.8 \mu \mathrm{g}$ of calcium $/ \mathrm{mg}$ of tissue).

Aortic wall: lysine and borohydride data

Table $\mathrm{V}$ summarizes the calcium levels of aortic wall tissues and their corresponding AOA levels. Before implantation, the tissue AOA levels were $69.6 \pm$ $1.4,17.8 \pm 0.8$, and $39.5 \pm 1.5 \mathrm{nM} / \mathrm{mg}$ of tissue for AOA, lysine-pretreated and $\mathrm{NaBH}_{4}$-pretreated aortic wall tissues, respectively. After 60 days of subdermal implantation, their calcium levels were also comparable (i.e., $71.4 \pm 5.4,82.8 \pm 7.6$, and $88.4 \pm 4.3 \mu \mathrm{g}$ of calcium $/ \mathrm{mg}$ of tissue). The control groups showed variable degrees of calcification, and the calcium content of lysine-pretreated aortic wall $(73.3 \pm 6.8 \mu \mathrm{g} / \mathrm{mg}$ of tissue) did not differ significantly from that of the group treated with both lysine and AOA (82.8 \pm 7.6 $\mu \mathrm{g} / \mathrm{mg}$ of tissue), but was significantly lower than that of the $\mathrm{NaBH}_{4}$-pretreated counterpart (138.8 \pm $14.5 \mu \mathrm{g} / \mathrm{mg}$ of tissue, $P<.001$ ).
Morphology

Histologically, as illustrated in Figure 5, the reduction of calcification in AOA-treated tissues was confirmed. Furthermore, the cuspal architecture of the AOA-pretreated explants was not different in appearance from unimplanted, noncalcified cusps. Calcification was not noted within the maximally treated cusps. Calcification of the AOA-treated aortic wall was slightly diminished relative to control tissue, but the calcification pattern was not morphologically unusual. The aortic wall calcification was principally oriented along the elastic laminae in both AOApretreated and non-AOA-exposed aortic wall explants.

\section{DISCUSSION}

The principal findings of this study were: 1) Pretreatment with AOA retarded the diffusion of calcium ions through BPHV aortic cusps, but not aortic wall. Reduction of calcium diffusion through cusps was directly related to increasing AOA levels. 2) A

TABLE V

Effects on Calcification (60-Day Rat Subdermal Implant) of Lysine and $\mathrm{NaBH}_{4}$ Pretreatment Before AOA on Aortic Wall

\begin{tabular}{|c|c|c|c|}
\hline Group & Treatment & $\begin{array}{c}\text { AOA Level } \\
(\mathrm{nM} / \mathrm{mg} \text { Tissue }) \pm \mathrm{SEM}\end{array}$ & $\begin{array}{c}\text { Tissue Calcium } \\
(\mu \mathrm{g} / \mathrm{mg} \text { Tissue }) \pm \mathrm{SEM}\end{array}$ \\
\hline I & Control (no treatment) & 0 & $104.9 \pm 8.5$ \\
\hline II & AOA treatment & $69.6 \pm 1.4$ & $71.4 \pm 5.4^{*,+}$ \\
\hline III & Lysine/then AOA treatment & $17.8 \pm 0.8$ & $82.8 \pm 7.6^{*}$ \\
\hline IV & Lysine only & 0 & $73.3 \pm 6.8$ \\
\hline $\mathrm{V}$ & $\mathrm{NaBH}_{4} /$ then AOA treatment & $35.9 \pm 1.5$ & $88.4 \pm 4.3$ \\
\hline VI & $\mathrm{NaBH}_{4}$ only & 0 & $138.3 \pm 14.5$ \\
\hline
\end{tabular}

Each data point represents the average of at least 10 replicates \pm SEM.

${ }^{*} P<.001$ as compared with group I.

${ }^{t} P<.001$ as compared with group VI. 
finite but significant amount of AOA remained tightly associated to either cusp or aortic wall regardless of aggressive solvent extraction. 3) Partially blocking AOA uptake with either lysine or sodium borohydride did not significantly diminish the AOA anticalcification effect for cusp or aortic wall, thus indicating the exposure time-dependent anticalcification effect of AOA.

\section{Calcium diffusion}

The presence of AOA on bioprosthetic cusp and aortic wall tissues greatly reduces the rate of calcium ion diffusion, and the extent of retardation of calcium diffusion appears to be proportional to the amount of AOA present on the tissues (see Fig. 2). In addition, the AOA dependency of calcium transport kinetics is consistent in both cusp and aortic wall tissues. The time span for calcium transport across aortic wall is much longer than that of cusp, which implies aortic wall is more impervious to calcium penetration. The differences in the diffusion time spans of the two types of tissues may be attributable to a number of material considerations, including the fact that aortic wall is much thicker (range of thickness $1.5-2.0 \mathrm{~mm}$ ) and has relatively greater amount of elastin. Last, the denser laminated architecture of aortic wall could also contribute to the great difference in calcium diffusion time span.

The gradual decrease of diffusivity of cusp tissues with increase in their AOA levels (see Table II) suggested an interaction between calcium ions and AOA molecules within the cuspal tissues. However, the difference in AOA levels on aortic wall tissues did not appear significantly to alter the diffusivities of calcium across the aortic wall tissue. This observation could be caused by the higher calcium retention capacity (due to greater thickness), and thus retention time, thereby masking the apparent effect of calcium ion-AOA interaction. Perhaps the presence of bound AOA on the tissue surface creates an unfavorable environment for the initial nucleation of calcium phosphates, and thereby hinders the eventual formation of hydroxyapatite. It is also conceivable that $\mathrm{AOA}$ could serve as a detergent to extract calcifiable materials (e.g., phospholipids) from bioprosthetic tissues, rendering them less susceptible to calcification.

\section{AOA extraction study}

Extraction studies of AOA-treated tissues (cusp and aortic wall) were performed to determine the stability of AOA binding. Initially, $\mathrm{pH} 7.4$ phosphate- buffered saline was used as a medium for the study. To better simulate the in vivo environment that a bioprosthetic heart valve would encounter after implantation, an AOA extraction study was also conducted using bovine serum as an alternative medium. Furthermore, because of the poor solubility of AOA in water, and hence in phosphate-buffered saline, extraction in this medium may thus reflect its dissolution characteristics rather than its binding stability. Therefore Tween 80 , a nonionic surfactant, was used as a dissociative medium to enhance nonbound $\mathrm{AOA}$ dissolution.

The results of the extraction study demonstrated that a small but significant amount of AOA remained tightly associated with the tissue (cusp or aortic wall), after 8 months, despite the harsh solvent condition (i.e., Tween 80 solution) used for extraction. This result may indicate that at least a sizable fraction of the AOA uptake could be covalently bound. A significant fraction of AOA could also be associated with the tissue via some other mechanisms (e.g., hydrophobic interaction). Thus, in the presence of a sink condition (i.e., Tween 80), this fraction of AOA dissociated almost immediately (see Fig. 3).

\section{Efficacy of AOA (duration of exposure) in rat subdermal model}

The results of rat subdermal implant study indicated that AOA has a definite exposure time-related anticalcification response on both cusp and aortic wall (see Table I and Fig. 4). Apparently, a minimum time exposure of tissue has to be achieved for anticalcification efficacy. The minimum time requirement for cusp was between 5 and $72 \mathrm{~h}$, and almost complete inhibition of calcification was achieved at $120 \mathrm{~h}$. The optimal exposure time for maximal inhibition of calcification of aortic wall was about $72 \mathrm{~h}$. Nevertheless, aortic wall was significantly more calcified than cusp tissue despite the AOA treatment. The differences in tissue compositions (i.e., collagen for cusp and elastin for aortic wall) as discussed earlier, and differences in mechanism could account for a differential in the initial AOA levels, and thus the differential anticalcification effect on the two types of tissues. Last, AOA may not alter the pathophysiology of aortic wall mineralization, which partially involves elastin calcification.

Efficacy of AOA in rat subdermal model: Blockade of glutaraldehyde residues with lysine and reduction of glutaraldehyde residues with sodium borohydride

The mode of AOA binding on aortic wall tissue was determined by either blocking or reducing the free 
glutaraldehyde residues pre-emptively, using lysine and $\mathrm{NaBH}_{4}$, respectively. Lysine has an $\mathrm{\epsilon}$-amino group, and thus can be expected to react readily with free aldehyde residues, thereby partially blocking the level of aldehyde reactions with AOA in subsequent treatments. The reaction between lysine and free aldehyde residues was validated in a previous study involving the use of ${ }^{14} \mathrm{C}$-lysine.${ }^{18} \mathrm{NaBH}_{4}$ is a reducing agent and is hypothesized to convert the free aldehyde functional groups into alcohol, thereby also partially reducing the binding of $\mathrm{AOA}$ in subsequent treatment. The calcium contents of subdermal explants of all the AOA treatment groups were comparable, and the control treatments (including lysine and $\mathrm{NaBH}_{4}$ ) were ineffective in inhibiting calcification. The implication of these results is that the length of time the cusp tissue is exposed to AOA solution appears to be more important in preventing calcification than their initial absolute AOA levels.

\section{Comparing AOA with other anticalcification agents}

Pretreating bioprosthetic heart valve cusps with sodium dodecyl sulfate (SDS) in rat subdermal implants ${ }^{19}$ and sheep circulatory implants, ${ }^{20}$ ferric ion and aluminum ion in rat subdermal studies, ${ }^{21}$ and also diphosphonate compounds (e.g., aminodiphosphonate) in rat subdermal studies ${ }^{18}$ has proven to be efficacious for inhibiting porcine aortic valve bioprosthetic calcification. Only the latter three agents were evaluated for their anticalcification efficacies on aortic wall in rat subdermal implants, ${ }^{22}$ and they were indeed effective. Nevertheless, their anticalcification efficacies for aortic wall were never assessed in a large animal circulatory implant. However, a recent study using glutaraldehyde-pretreated rat aortic valve allograft implants (as aortic vascular grafts in rats) has demonstrated that either ferric chloride or aluminum chloride was effective in inhibiting aortic wall calcification. $^{23}$

The presence of calcification in the aortic wall portion of stent-mounted porcine valve is rarely of clinical significance. Recently, the introduction of stentless porcine aortic valves (composed of both cusp and aortic wall) for clinical use $\mathrm{e}^{24,25}$ has raised further questions about possible obstruction due to aortic wall calcification. It was demonstrated in a recent study that the aortic wall portion of stentless valve (implanted in sheep as an apicoaortic shunt) calcified extensively despite AOA pretreatment before implantation. ${ }^{7}$ This result raises the possibility that the development of calcified nodules on aortic wall could indeed cause obstruction of stentless allografts. This notion is further supported by the fact that calcific stenosis of the aortic wall was the primary cause of the failure of cryopreserved homograft valves in a recent study. ${ }^{26}$

\section{CONCLUSIONS}

${ }^{14} \mathrm{C}$-labeled 2-amino oleic acid pretreatment of glutaraldehyde preserved porcine aortic valve bioprostheses was more effective in mitigating cusp than aortic wall calcification in rat subdermal implants, and the anticalcification effect appears to be dependent more on the amount of time tissues are exposed to AOA than on their actual AOA levels. Bound AOA diminished $\mathrm{Ca}^{2+}$ diffusion into BPHV (cusps but not aortic wall), and the reduced rate of diffusion appears to be directly related to the increasing amount of AOA bound to aortic cusps. This may explain in part the anticalcification mechanism of AOA for cusps but not the aortic wall.

These studies were supported by grants and contracts to the University of Michigan (W.C. and R.J.L.) from the Heart Valve Division of Medtronic (Irvine, CA).

\section{References}

1. F. J. Schoen, R. J. Levy, and H. R. Piehler, "Pathological considerations in replacement cardiac valves," Cardiovasc. Pathol., 1, 29-52 (1992).

2. F. J. Schoen and R. J. Levy, "Calcification of bioprosthetic heart valves," in Replacement Heart Valves, E. Bodnar and R. Frater (eds.), Pergamon Press, New York, 1989, pp. 124-148.

3. I. Gallo, F. Nistal, E. Artinano, D. Fernandez, R. Cayon, M. Carrion, and V. Garcia-Martinez, "The behavior of pericardial versus porcine valve xenografts in the growing sheep model," I. Thorac. Cardiovasc. Surg., 93, 281-290 (1987).

4. F. J. Schoen, R. J. Levy, A. C. Nelson, W. F. Bernhard, A. Nashef, and M. Hawley, "Onset and progression of experimental bioprosthetic heart valve calcification," Lab. Invest., 52, 523-532 (1985).

5. M. N. Girardot, J. M. Girardot, and F. J. Schoen, "Alpha amino oleic acid, a new compound, prevents calcification of bioprosthetic heart valve," Trans. Soc. Biomater. 14, 114 (1991).

6. J. P. Gott, Pan-Chih, L. M. A. Dorsey, J. L. Jay, G. K. Jett, F. J. Schoen, J. M. Girardot, and R. A. Guyton, "Calcification of porcine valves: A successful new method of antimineralization," Ann. Thorac. Surg., 53, 207-216 (1992).

7. W. Chen, F. J. Schoen, and R. J. Levy, "Mechanism of efficacy of 2-amino oleic acid for inhibition of calcification of glutaraldehyde pretreated porcine bioprosthetic heart valves," Circulation, 90, 323-329 (1994).

8. E. A. Woodroof, "Use of glutaraldehyde and formaldehyde to process tissue heart valve," J. Bioeng., 2, 1-9 (1978).

9. D. T. Cheung and M. E. Nimni, "Mechanism of crosslinking of proteins by glutaraldehyde: I. Reaction of 
model compounds," Connect. Tissue Res., 10, 187-199 (1982).

10. A. H. Korn, S. H. Feairheller, and E. M. Filachione, "Glutaraldehyde: Nature of the reagent," J. Mol. Biol., $65,525-529$ (1972).

11. J. M. Girardot, "A method for retarding or preventing the calcification of a prosthesis implanted in a mammal," U.S. patent no. 4,976,733.

12. R. Baker, "Diffusion controlled systems," in Controlled Release of Biologically Active Agents, R. Baker (ed.), Wiley Press, New York, 1986, pp. 39-83.

13. T. P. Johnston, J. A. Boyd, B. L. Ciesliga, F. J. Schoen, G. L. Amidon, and R. J. Levy, "Controlled release of ethanehydroxy diphosphonate from polyurethane reservoirs to inhibit calcification of bovine pericardium used in bioprosthetic heart valves," Int. J. Pharmacol., 59, 95-104 (1990).

14. G. R. Barnhart, M. Jones, T. Ishihara, A. M. Chavez, D. M. Rose, and V. J. Ferrans, "Failure of porcine aortic and porcine aortic and bovine pericardial prosthetic valves: An experimental investigation in young sheep," Circulation, 66(Suppl. I), 1-50 (1982).

15. F. J. Schoen, J. W. Tsao, and R. J. Levy, "Calcification of bovine pericardium used in cardiac valve bioprostheses: Implication for the mechanisms of bioprosthetic tissue mineralization," Am. I. Pathol., 123, 134 145 (1986).

16. M. J. Karnovsky, "A formaldehyde-glutaraldehyde fixative of high osmolality for use in electron microscopy," J. Cell Biol., 27, 137A-138A (1965).

17. M. J. Thubrikar, J. D. Deck, J. Aouad, and S. P. Nolan, "Role of mechanical stress in calcification of aortic bioprosthetic valves," $J$. Thorac. Cardiovasc. Surg., 86, 115-125 (1983)

18. C. L. Webb, J. J. Benedict, F. J. Schoen, J. A. Linden, and R. J. Levy, "Inhibition of bioprosthetic heart valve calcification with aminodiphosphonate covalently bound to residual aldehyde groups," Ann. Thorac. Surg., 46, 309-316 (1988).

19. D. H. Hirsch, J. Drader, T. J. Thomas, F. J. Schoen,
J. T. Levy, and R. J. Levy, "Inhibition of calcification of glutaraldehyde pretreated porcine aortic cusps with sodium dodecyl sulfate: Preincubation and controlled release studies," J. Biomed. Mater. Res., 27, 1477-1484 (1993).

20. M. Jones, E. E. Eidbo, S. L. Hilbert, V. J. Ferrans, and R. E. Clark, "The effects of anticalcification treatments of bioprosthetic valves implanted in sheep," Trans. Am. Soc. Artif. Intern. Organs, 34, 1027-1030 (1988).

21. R. J. Levy, F. J. Schoen, W. B. Flowers, and S. T. Staelin, "Initiation of mineralization in bioprosthetic heart valves: Studies of alkaline phosphatase activity and its inhibition by $\mathrm{AlCl}_{3}$ or $\mathrm{FeCl}_{3}$ preincubation," J. Biomed. Mater. Res., 25, 905-935 (1991).

22. C. L. Webb, L. L. Phelps, F. J. Schoen, and R. I. Levy, "Aminodiphosphonate or $\mathrm{Al}^{3+}$ preincubation inhibits calcification of homografts in rat subdermal model," Trans. Am. Soc. Artif. Intern. Organs, 34, 851854 (1988).

23. R. J. Levy, X. Qu, T. Underwood, F. J. Schoen, and J. Trachy, "Effects of calcification inhibitors on glutaraldehyde pretreated aortic valve allografts in rats," Trans, Soc. Biomater., 16, 256 (1993).

24. W. Konetz, P. Hamann, E. Schwammenthal, G. Breithardt, and H. H. Scheld, "Aortic valve replacement with stentless xenografts," J. Heart Valve Dis., 1, 249252 (1992)

25. T. E. David, J. Bos, and H. Rakowski, "Aortic valve replacement in Toronto SPV bioprosthesis," J. Heart Valve Dis., 1, 244-248 (1992).

26. D. C. Cleveland, W. G. Williams, A. J. Razzouk, G. A. Trusler, I. M. Rebeyka, L. Duffy, Z. Kan, J. G. Coles, and R. M. Freedom," Failure of cryopreserved homograft valved conduits in the pulmonary circulation," Circulation, 86(5 Suppl), II150-II153 (1992).

Received January 18, 1994

Accepted July 1, 1994 